\title{
PEMANFAATAN VEGETASI MANGROVE DI PULAU PADANG TIKAR KECAMATAN BATU AMPAR KABUPATEN KUBU RAYA
}

\author{
(The Utilization of Mangrove Vegetation in Padang Tikar Island Batu Ampar District Kubu \\ Raya Regency)
}

\author{
Ratnasari, Fahrizal, M. Dirhamsyah \\ Fakultas Kehutanan Universitas Tanjungpura. Jln Imam Bonjol Pontianak 78124 \\ E-mail : sariratna350@gmail.com
}

\begin{abstract}
Utilization of natural resources by the community sometimes does not pay attention to the limits of ability or environmental carrying capacity in the regeneration process for sustainable life cycle, both biologically, physically, ecologically and economically. Optimal and environmentally sound utilization and management of natural resources is required to support the sustainability of natural resources including mangrove forests. Mangrove forest is one type of tropical rainforest located along the coastline of tropical waters. This forest is a transition of terrestrial and marine environment habitat. One of the mangrove forest in West Kalimantan is located on Pulau Padang Tikar Batu Ampar Sub-district of Kubu Raya Regency with mangrove forest area of approximately 58,953 $\mathrm{Ha}$ which consists of 11 villages inside the forest. The purpose of this research is to know the types of mangrove vegetation and the utilization of mangrove vegetation by the community in 11 villages of Pulau Padang Tikar. This research uses survey method with interview technique. Numbers of respondents were 10 people from each village (total number 110 respondents) in Pulau Padang Tikar. Results of the research found 20 mangrove vegetation species found in the community and 9 types of mangrove vegetation are used for firewood, building material, charcoal, honey bee cultivation and herbal medicines. The species found were Acanthus ilicifolius, Acrostichum aureum, Avicennia sp. Amyema anisomeres, Bruguiera parviflora, Excoecaria agallocha, Heritiera globosa, Kandelia candel, Lumnitzera littorea, Nypa fruticans, Rhizophora sp., Sonneratia alba, Sonneratia caseolaris, Xylocarpus granatum, Oncosperma tigilarium, Hibiscus tiliaceus, Ipomea pescaprae, Sonneratia sp, Bruguiera cylindrica and Sonneratia ovata back.
\end{abstract}

Keywords : Batu Ampar, Kubu Raya Regency, mangrove, Pulau Padang Tikar, Utilization

\section{PENDAHULUAN}

Sumber daya alam merupakan aset penting suatu negara dalam melaksanakan pembagunan, khususnya pembangunan di sektor ekonomi. Selain dipergunakan untuk memenuhi kebutuhan hidup manusia, sumberdaya alam juga menberikan kontribusi yang cukup besar bagi kesejahteraan suatu negara. Oleh karena itu pemanfaatan dan pengelolaan sumberdaya alam secara optimal, lestari dan berwawasan lingkungan sudah semestinya di lakukan (Sukmawan,2004).
Indonesia memiliki ekosistem mangrove terluas di dunia, yaitu sekitar $27 \%$ dari total hutan mangrove dunia (16 juta ha). Jenis mangrove yang tercatat mencapai 158 jenis, terdiri dari 89 jenis pohon, 2 jenis palem 19 jenis liana, 44 jenis epifit dan 1 jenis sikas (Bengen, 2002). Kalimantan Barat menpunyai kawasan hutan mangrove terluas di indonesia dengan lauasan sekitar $119.327 \mathrm{Ha}$, memiliki $75 \%$ jenis mangrove yang hidup di indonesia. Kawasan hutan mangrove di 
Kalimantan Barat sendiri meliputi wilayah Ketapang, Kayong Utara, Kubu Raya, Menpawah, Singkawang dan Kabupaten Sambas (SAMPAN Kalimantan,2015).

Manfaat dan peran vegetasi mangrove secara langsung yang dirasakan oleh masyarakat di Pulau Padang Tikar adalah: menstabilkan pantai dengan menahan ombak yang menuju daratan, sebagai lumbung makanan (kepah, kepiting, ikan, madu dan bahan makanan olahan dari daun mangrove), serta sebagai bahan papan (untuk membuat rumah, sampan dan perahu) dan etnobotani (obat-obatan). Dalam pemanfaatan vegetasi mangrove, masyarakat Pulau Padang Tikar memanfaatkan sesuai dengan kearifan lokal. Kearifan lokal merupakan konsepsi umum yang terorganisasi, mempengaruhi perilaku yang berhubungan dengan alam, kedudukan manusia dalam alam, (Sartini, 2009).

Definisi ekosistem mangrove merupakan vegetasi pohon didaerah tropis yang terdapat kawasan intertidal (pasang surut) dan mendapat pasokan air asin laut dan air tawar rawa gambut (payau). Karakteristik hutan mangrove diantaranya yaitu memiliki habitat substrat yang berlumpur, lempung dan berpasir, substrat ini sangat berpengaruh terhadap ekosistem atau spesies yang tinggal dalam kawasan tersebut (Noor et. al, 1999).

Menurut Ghufran (2012) yang di pengaruhi adanyan perbedaan penggenangan atau perbedaan salinitas yang meliputi:

1. Zona garis pantai, yaitu kawasan yang berhadapan langsung dengan laut. Lebar zona ini sekitar 10-75 meter dari garis pantai .

2. Zona tengah, merupakan kawasan yang terletak di belakang zona garis pantai dan memiliki lumpur liat.
3. Zona belakang, yaitu kawasan yang berbatasan dengan hutan darat.

\section{METODE PENELITIAN}

Penelitian dilaksanakan di Pulau Padang Tikar Kecamatan Batu Ampar, Kabupaten Kubu Raya yaitu desa Batu Ampar, desa Teluk Nibung, desa Nipah Panjang, desa Medan Mas, Desa Padang Tikar 1, Desa Padang Tikar 2, desa Tasik Malaya, desa Sungai Basar, desa Sungai Jawi, Desa Ambarawa dan desa Tanjung Harapan. Luasan kawasan hutan mangrove kurang lebih 58,953 Ha dengan waktu pelaksanaan penelitian selama 2 (empat) minggu di lapangan.

Objek penelitian adalah masyarakat di 11 desa Pulau Padang Tikar, adapun alat dan bahan yang digunakan pada penelitian ini adalah :

1. Alat tulis, untuk mencatat data selama dilapangan

2. Kuisioner sebagai alat bantu saat wawancara dengan responden

3. Kamera untuk dokumentasi selama penelitian

4. Peta lokasi penelitian

5. Buku identifikasi tumbuhan mangrove

6. Recorder untuk merekam suara saat wawancara dengan responden

7. GPS untuk menbuat track perjalanan selama penelitian.

Metode penelitian yang digunakan adalah dengan menggunakan metode survei dengan teknik wawancara Teknik pengumpulan data dilakukan secara langsung dengan komunikasi yang dibantu kuesioner (Singarimbun, dkk 1989).

Data primer adalah data pokok yang diperoleh dengan wawancara langsung terhadap masyarakat (responden) dengan mengunakan kuesioner. Data yang dikumpulkan adalah data potensi sumber daya mangrove dan pemanfaatan mangrove 
oleh masyarakat 11 desa Pulau Padang Tikar.

Data sekunder adalah data yang diperoleh tidak langsung dari respondeen, melalui pihak lain yang terkait dengan penelitian ini dalam bentuk dokumen. Data sekunder dapat diperoleh dari instasi terkait, lembaga terkait, hasil-hasil dari penelitian (skripsi dan tesis), literatur relevan (jurnal ilmiah), buku yang berhubungan dengan penelitian pemanfaatan hutan mangrove.

\section{HASIL DAN PEMBAHASAN}

Berdasarkan hasil pengamatan dilapangan dengan menggunakan metode survei dengan teknik wawancara ditemukan 20 jenis vegetasi mangrove yang di ketahui oleh masyarakat. Sedangkan vegetasi mangrove yang di manfaatkan oleh masyarakat di Pulau Padang Tikar Kecamtan Batu Ampar, Kabupaten Kubu Raya berjumlah 9 vegetasi, pemanfaatan dari vegetasi mangrove tersebut antara lain untuk kayu bakar, bahan bangunan, produksi arang, budidaya lebah madu dan untuk obatobatan herbal. Nama-nama jenis vegetasi mangrove yang di temukan di Pulau Padang Tikar Kecamatan Batu Ampar, Kabupaten Kubu Raya di sajikan pada Tabel 1 dan Tabel 2.

Tabel 1. Jenis-jenis vegetasi mangrove yang ditemukan di Pulau Padang Tikar, Kecamatan Batu Ampar Kabupaten Kubu Raya, Provinsi Kalimantan Barat (Type of mangrove vegetation at Pulau Padang Tikar, Batu Ampar sub district Kubu Raya Regency, Kalimantan Barat Province)

\begin{tabular}{llll}
\hline No & Nama Lokal & Nama Ilmiah & Famili \\
\hline 1. & Jeruju & Acanthus ilicifolius & Acanthaceae \\
2. & Piai & Acrostichum aureum & Pteridaceae \\
3. & Api-api & Avicennia sp. & Avicenniaceae \\
4. & Banalu bakau & Amyema anisomeres & Loranthaceae \\
5. & Tumuk & Bruguiera parviflora & Rhizophoraceae \\
6. & Buta-buta & Excoecaria agallocha & Euphorbiaceae \\
7. & Dungun & Heritiera globosa & Sterculiaceae \\
8. & Kandelia & Kandelia candel & Rhizophoraceae \\
9. & Teruntum & Lumnitzera littorea & Combretaceae \\
10. & Nipah & Nypa fruticans & Arecaceae \\
11. & Bakau & Rhizophora sp. & Rhizophoraceace \\
12. & Perepat & Sonneratia alba & Sonneratiaceae \\
13. & Berembang & Sonneratia caseolaris & Sonneratiaceae \\
14 & Nyirih & Xylocarpus granatum & Meliaceae \\
15 & Nibung & Oncosperma tigilarium & Araceae \\
16. & Waru laut & Hibiscus tiliaceus & Malvaceae \\
17. & Kacang laut & Ipomea pescaprae & Convolvulaceae \\
18. & Pedada & Sonneratia sp & Lythraceae \\
19. & Tanjang & Bruguiera cylindrica & Rhizophoraceae \\
20 & Kedabu & Sonneratia ovata back & Lythraceae \\
\hline
\end{tabular}


JURNAL TENGKAWANG (2017)

Vol. 7 (2) : 110 - 115

Tabel 2.Jenis Vegetasi Mangrove yang di Manfaatkan oleh Masyarakat di Pulau Padang Tikar, Kecamatan Batu Ampar Kabupaten Kubu Raya, Provinsi Kalimantan Barat (Plants of mangrove used by the community at Pulau Padang Tikar, Batu Ampar sub district Kubu Raya Regency, Kalimantan Barat Province)

\begin{tabular}{|c|c|c|c|c|}
\hline \multirow[t]{2}{*}{ No } & \multirow[t]{2}{*}{ Nama Lokal } & \multicolumn{2}{|c|}{ Nama } & \multirow[t]{2}{*}{ Pemanfaatan } \\
\hline & & Ilmiah & Famili & \\
\hline 1. & Jeruju & $\begin{array}{l}\text { Acanthus } \\
\text { ilicifolius }\end{array}$ & Acanthaceae & $\begin{array}{l}\text { 1. Daun bisa di jadikan } \\
\text { bahan makanan ringan } \\
\text { (keripik) } \\
\text { 2. Buah bisa digunakan } \\
\text { untuk obat bisul }\end{array}$ \\
\hline 2. & Piai & $\begin{array}{l}\text { Acrostichum } \\
\text { aureum }\end{array}$ & Pteridaceae & $\begin{array}{l}\text { 1. Daun sebagai alas } \\
\text { kandang untuk memilihara } \\
\text { ternak } \\
\text { 2. Spora di gunakan untuk } \\
\text { pengobatan pencegahan } \\
\text { penyakit bisul }\end{array}$ \\
\hline 3. & Api-api & Avicennia & Avicenniaceae & $\begin{array}{l}\text { Batang gunakan sebagai } \\
\text { bahan bangunan dan kayu } \\
\text { bakar }\end{array}$ \\
\hline 4. & Buta-buta & $\begin{array}{l}\text { Excoecaria } \\
\text { agallocha }\end{array}$ & Euphorbiaceae & $\begin{array}{l}\text { Anti radang dengan } \\
\text { menggunakan kulit kayunya }\end{array}$ \\
\hline 5. & Nipah & $\begin{array}{l}\text { Nypa } \\
\text { fruticans }\end{array}$ & Arecaceae & $\begin{array}{l}\text { Buah bisa dijadikan bahan } \\
\text { makanan (tepung,kalang } \\
\text { kaling dan sirup) }\end{array}$ \\
\hline 6. & Bakau & Rhizophora & Rhizophoraceae & $\begin{array}{l}\text { 1. Batang bisa digunakan } \\
\text { sebagai bahan bangunan } \\
\text { 2. Batang bisa digunakan } \\
\text { sebagai arang } \\
\text { 3. Batang bisa digunakan } \\
\text { sebagai bahan bakar } \\
\text { 4. Bisa dimanfaatkan untuk } \\
\text { obat-obatan } \\
\text { 5. Budidaya lebah madu }\end{array}$ \\
\hline 7. & Perepat & $\begin{array}{l}\text { Sonneratia } \\
\text { alba }\end{array}$ & Sonneratiaceae & $\begin{array}{l}\text { Batang digunakan sebagai } \\
\text { bahan bangunan }\end{array}$ \\
\hline 8. & Nyirih & $\begin{array}{l}\text { Xylocarpus } \\
\text { granatum }\end{array}$ & Meliaceae & $\begin{array}{l}\text { 1. Batang digunakan sebagai } \\
\text { bahan bangunan } \\
\text { 2. Batang tempat } \\
\text { bersarangnya lebah madu } \\
\text { hutan Apis } \\
\text { dorsata(budidaya madu) } \\
\text { 3. Buah digunakan sebagai } \\
\text { obat demam (panas tinggi) }\end{array}$ \\
\hline 9. & Nibung & $\begin{array}{l}\text { Oncosperma } \\
\text { tigilarium }\end{array}$ & Araceae & 1. Sebagai bahan bangunan \\
\hline
\end{tabular}




\section{KESIMPULAN}

1. Jenis vegetasi mangrove yang masyarakat/reponden ditemukan berjumlah 20 jenis dan yang di manfaatkan 9 jenis vegetasi mangrove, baik itu dimanfaatkan untuk budidaya madu, bangunan, arang, obat-obatan dan kayu bakar.

2. Pemanfaatan vegetasi mangrove yang dilakukan oleh masyarakat Pulau Padang Tikar untuk kayu bakar adalah dengan mengolah vegetasi mangrove dengan cara memotong kayu sesuai dengan keperluan

3. Pemanfaatan vegetasi mangrove untuk keperluan bangunan, masyarakat harus menebang dan memotong kayu yang diperlukan sesuai dengan keperluan.

4. Pemanfaatan vegetasi mangrove untuk produksi arang yang dilakukan oleh masyarakat Pulau Padang Tikar

1. Jumlah vegetasi manrove yang di ketahui oleh masyarakat hanya 20 jenis dan yang dimanfaatkan oleh masyarakat maka diperlukannya suatu proses pengiventarisasi dan pemanfaatan setiap jenis dari vegetasi mangrove yang ada di Pulau Padang Tikar.

2. Diperlukan sosiali kepada masyarakat tentang nama jenis dan pemanfaatan vegetasi mangrove yang ada di Pulau Padang Tikar

3. Pemanfaatan vegetasi mangrove untuk keperluan kayu bakar, bangunan yang dilakukan oleh masyarakat di setiap desa yang ada di Pulau Padang Tikar adalah dengan cara menebang kayu-kayu dari tanaman bakau dan nyirih, walaupun dalam skala kecil namum masyarakat wajib menperhatikan dampak dari penebangan kayu-kayu tersebut dalam jangka panjang adalah dengan menebang, mengumpulkan dan menbakar kayu kedalam pondok arang dan kemudian baru bisa di produksi sesuai dengan kelas pasaran arang.

5. Pemanfaatan vegetasi mangrove untuk budidaya lebah madu adalah salah satu pemanfaatan vegtasi mangrove yang di rasakan oleh masyarakat di Pulau Padang Tikar karena masyarakat bisa langsung memanen madu yang di hasilkan oleh lebah secara langsung dipohon tempat lebah hinggap.

6. Pemanfaatan vegetasi mangrove untuk keperluan obat-obatan tidak banyak di lakukan oleh masyarakat Pulau Padang Tikar, namun jika di perlukan sesuai masyarakat mengolah tanaman-tamanan yang di butuhkan untuk pengobatan herbal

\section{SARAN}

4. Perlu adanya sosialisasi kepada masyarakat di desa Batu Ampar khususnya dan masyakat Pulau Padang Tikar terhadap kerusakan dan pemusnahan dari vegetasi mangrove yang yang ada di Pulau Padang Tikar akibat dari pengambilan vegetasi mangrove untuk menproduksi arang.

5. Menbentuk usaha/lahan pekerjaan baru untuk masyarakat yang menproduksi arang agar vegetasi mangrove yang ada di Pulau Padang Tikar tetap lestari untuk masa depan.

\section{DAFTAR PUSTAKA}

Ghufan M, 2012. Ekosistem Mangrove Potensi, Fungsi dan Pengelolaan. Rineka Cipta. Jakarta

Noor R, Khazali Y.,M., dan Suryadiputra I N.N. 1999. Paduan Pengenalan Mangrove di Indonesia. PHKA/WI-IP, Bogor. 
JURNAL TENGKAWANG (2017)

Vol. 7 (2) : 110 - 115

SAMPAN Kalimantan, 2015. Proposal Rencana Kerja Pengelolaan Hutan DesaBentang Pesisir Padang Tikar. Pontianak

Sartini, N W. 2009, Menggali nilai kearifan lokal budaya jawa lewat ungkapan (bebasan, seoke dan paribasa) jurnal ilmiah bahasa dan satra volume V No 1 April 2009
Singarimbun, Masri, dan Effendi S. 1989. Metode Penelitian Survey. LP3ES. Jakarta.

Sukmawan, D. 2004. Penilaian Ekonomi Manfaat Hutan Mangrove di Desa Kalangjaladri Kecamatan Parigi, Kabupaten Ciamis, Provinsi Jawa Barat. IPB. Bogor. 